\title{
HOUSE SPARROWS FEEDING ON MALACOSOMA MOTHS
}

WALTER V. KRIVDA, Box 864, The Pas, Manitoba.

It is well known that birds catch, kill and eat insects. There is, however, very little literature as to particular species being eaten.

I, therefore, found it surprising and instructive to watch House Sparrows flying to and partly alighting on a perpendicular brick wall and taking resting Malacosoma Moths (Malascoma americana). The moths had swarmed the night before, 20 July 1973, and were on a north wall in the shade. There were perhaps four to six moths per square foot. It was a hot afternoon.

The House Sparrows were making periodic forays out of the 40-foot high Elms in downtown Winnipeg, Manitoba, to the wall. There was an audible sound made by the beak of the sparrow as it hit the brick wall while taking a moth. The birds would return to the trees to eat the moths. This could be seen from time to time the whole afternoon. The wings were discarded as the moth was eaten.

In a few instances a patch of Malacosoma eggs could be seen smeared on the wall where the impact of the bird's beak had struck the wall - crushing the moth.

A good study series of many dozen Malacosoma was collected on Portage Avenue, Winnipeg. All the specimens are pinned and are in the writer's collection at The Pas. More than one species of Malacosoma may be involved here.

In the next few days similar patches of smeared Malacosoma eggs were seen on the walls of buildings in different parts of the city. The Malacosoma flight was extensive. This may have been a general and suddenly learned response to an edible species of moth. House Sparrows are recent arrivals here perhaps 1890.

Different birds evidently learn at different rates as to what insects are edible. These changes have evidently been swift. House Sparrows living in the cities or towns, regularly pick up moths of many species in the early morning that have gathered on shop windows. This essentially is an unnatural accumulation, recently more accentuated by street lamps being changed over to mercury vapor lights. These draw more insects and moths in particular. The number of sparrows has also increased.

I can speak with some authority in that I have been collecting rather intensively for 30 years in The Pas area. A great amount of material is available for study.

The numerical changes that have taken place are rather interesting. In the two decades of the ' 50 s and ' 60 s it was possible to collect about 50 specimens of moths in a summer's morning to, say, 0800 in two town blocks of shop windows. Today, by 0800 one would be lucky to collect 6 to 12 specimens in a half hour of searching and collecting. Birds awake very early and fly from shop window to shop window ledge, picking up a variety of moths. They then kill the moths in the gutters or 


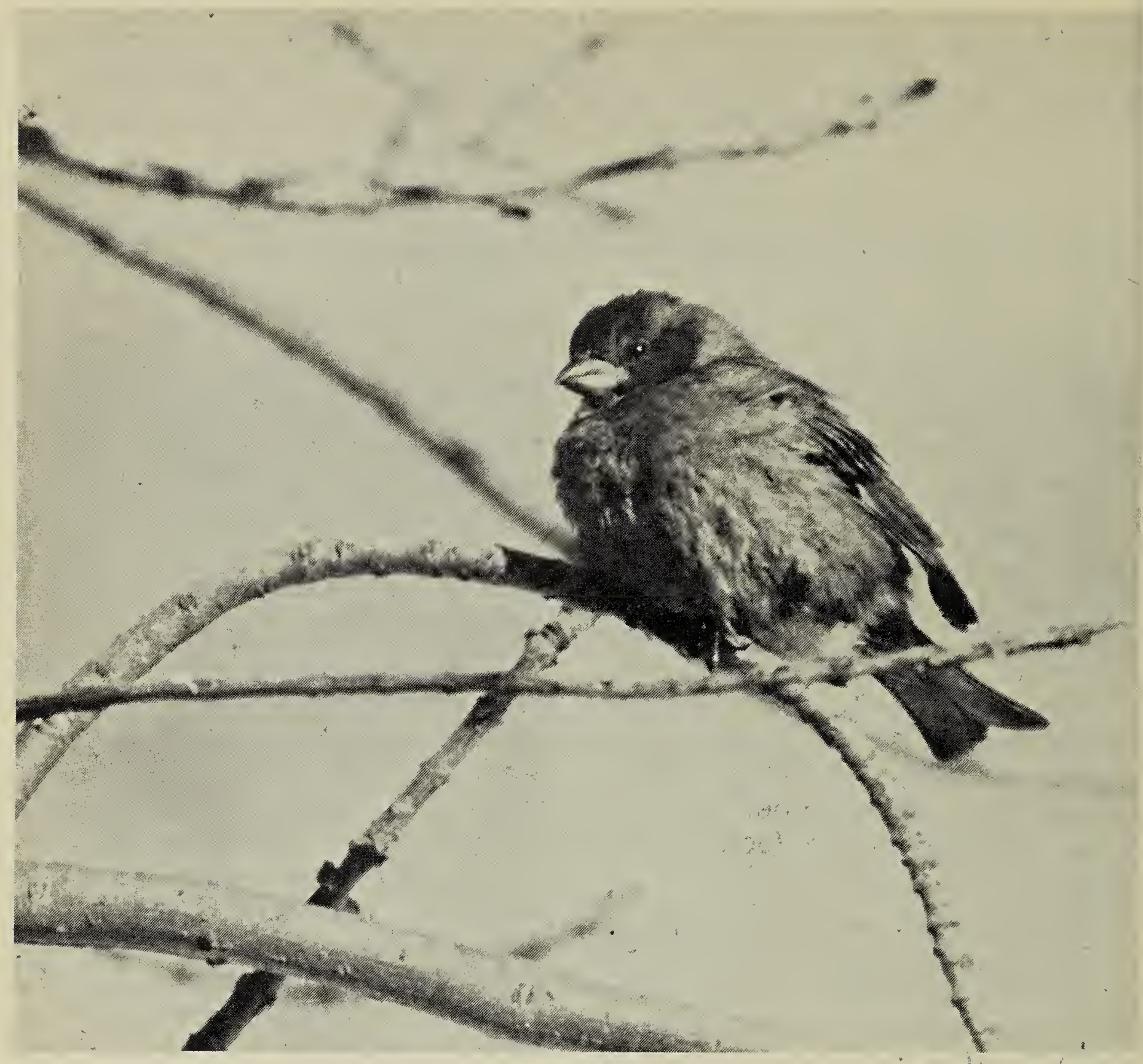

Female House Sparrow.

Robert.J. Long

cement sidewalks by pecking and then eating them by dismemberment.

In 1961, 1962 and 1963 I noted House Sparrows at Riding Mountain National Park, at Wasagaming, Manitoba, exploring the front grates of parked cars, often loaded with insects, that had just come from a distance.

In early June, various warblers, in their northward migration, would do the same here. They become expert in carefully examining all parts of the car grating. Any insects that flutter to the ground are immediately eaten.
Evidently not all insects are equally relished. Some fishflies and dragonflies caught in the grating were left uneaten.

House Sparrows, resident as they are throughout the year, now exert a considerable pressure on moth populations in city areas. This may reduce moth species and populations in urban areas for reasons other than chemical pollution.

Someone armed with a grant and expertise in collecting and observing should research this problem. It has possibilities of classical dimension. 